\title{
"SHROUD" - THE RELEVANCE OF THE STORY
}

\section{"कफन" - कहानी की प्रासंगिकता}

\author{
Dr. Ushakumari. K. P. ${ }^{* 1} \bowtie$
}

${ }^{* 1}$ Associate Professor, Department of Hindi, Mahatma Gandhi College, Thiruvananthapuram, India

DOI: https://doi.org/10.29121/granthaalayah.v8.i8.2020.924

Article Type: Research Article

Article Citation: Dr. Ushakumari. K. P.. (2020). "SHROUD" - THE RELEVANCE OF THE STORY. International Journal of Research -GRANTHAALAYAH, 8(8), 132-134. https://doi.org/10.29121/granthaalayah.v8.i8.2020.924

Received Date: 30 July 2020

Accepted Date: 25 August 2020

Keywords:

कफन

प्रासंगिकता

कहानी

\section{1. प्रस्तावना}

दिनेश गाँव में छोटा-मोटा बढ़ई का काम करता था। वैसे भी ये बढ़ई जो होते हैं चार दिन अगर काम कर लेते हैं, तो अगले चार दिन दिखाई नहीं देते। इन लोगों को बुलाते-बुलाते गला सूख जाता है। लेकिन इनके सिर पर जूं तक नहीं सरकता। जब दिनेश काम पर नहीं जाता, तो अपने चारों के संग शराब पीने और ताश खेलने निकल पड़ता है। पैसे सब जब खत्म हो जाएं तो महाशय फिर काम करने निकल पड़ते हैं। उसका एक लड़का है मोहन, वह एक सिरफिरा लड़का, काम-धाम कुछ नहीं, हाँ ड्राइविंग सीख लिया था बस। गावें में जौनसन वक़ील की कार चलाने जाता है, वे भी रोज - रोज़ नहीं, बल्कि जब वकील के परिवार में किसी को बाहर कहीं जाना हो तो इसे बुला लिया जाता था। घर पर पड़ा खाता-पीता था, उसे शराब पीने की लत भी थी। मोहन की पत्नी शीतल एक बड़े कपड़े की दुकान में सेल्सगर्ल का काम करती थी। बेचारी सुबह नौ बजे घर का काम और खाना वैगरह बना कर नौकरी पर निकल जाती और शाम सात बजे वापस आती। यूँ कहना होगा कि घर का सारा खर्चा उसे ही संभालना पड़ता था। कभी-कभार रविवार को बाप-बेटे, मछली या मुर्गा खरीद कर ले आते थे, और शराब पीने दोनों बैठ जाया करते, बाद में दोनों में बहुत बहस और झगड़ा शुरु हो जाता, गालियों की वर्षा करने लगते, जिससे आस-पड़ोस के लोग इन दोनों का भला-बूरा कहते। दूसरे दिन बेचारी शीतल लोगों से माफ़ी माँगती फिरती थी। शीतल ने ही ये किराये का मकान लिया था। वही किराया भी देती थी। वह इन दोनों को इसलिए झेलती, क्योंकि उसके माता-पिता का देहान्त हो चुका था और उसका कोई दूसरा बन्धु-मित्र नहीं था। वह बिलकुल लाचार थी।

सुबह दूधवाला आता है - "भैया दूध के पैसे दे दो"।

- "शीतल घर पर नहीं है, शाम को आ के ले जाना। "मोहन उसे डाँटते हुए कहता है। दिनेश ने तब मोहन से पूछा - "क्यों तेरे पास नहीं है क्या रुपये देने को।"

- "तुम्हारे पास हो तो दे दो। "कह कर मोहन गुस्से में घर के बाहर निकल जाता है।

- 'मैं कैसे, और क्यों दूँ, मैं तो यहाँ चाय नहीं पीता।' दिनेश बड़बड़ाता है।

(c) 2020 The Author(s). This is an open access article distributed under the terms of the Creative Commons Attribution License, which permits unrestricted use, distribution, and reproduction in any medium, provided the original author and source are credited. 
घर का ज़्यादातर खर्चा शीतल ही संभालती है।

शीतल बी.ए. पास थी। उसका बस एक ही सपना था, अपना एक 'छोटा' घर हो। उस सपने को साकार करने के लिए वह जी तोड़ मेहनत करती थी। रविवार के दिन आस-पड़ोस के छोटे बच्चों को पढ़ाती और उससे जो पैसे मिलते, उसे वह ज़मा कर रखती। नाम की तरह वह बहुत ही शान्त और सुशील लड़कीं थी। लेकिन मोहन शराब के नशे में शीतल को मारता-पीटता था। वह चुप रहती। सब कुछ सह लेती। इसी आस पर की कभी - सब अच्छा हो जाएगा, अपना घर, बच्चे, सुख-शान्ती।

उस दिन शाम के चार बजे शीतल का पड़ौसी भागता हुआ, शीतल के पास दुकान पर पहुँचा, हाँफता हुआ कहता है - "दीदी! मोहन को पुलिस पकड़ कर ले गई!"

शीतल घबरा जाती है - "क्यों क्या हुआ ?"

- "मैं नहीं जानता दीदी! मोहन ने पी रखी थी, पुलिस उसे मार-मार कर कह रही थी कि गुंडागर्दी करके - घर पर धुप कर बैठा है, क्यों बे।"

शीतल जल्दी से एक ऑटो में पुलिस-स्टेशन जाती है और तब पता चलता है कि, मोहन ने बस-स्टैंड पर किसी को मारा, उसके सिर पर चोट लगी है और उसे अस्पताल ले जाया गया है। शीतल फिर भागी वक़ील के पास आती है थोड़े-बहुत रूपये जो उसने ट्यूशन करके ज़मा कर रखे थे, वक़ील को देकर अपने पति को पुलिस स्टेशन से अपने जमानत पर छुड़ाती है।

मोहन शीतल से कहता है - "अब मैं कभी ऐसा कुछ नहीं करूँगा। उस साले ने मुझे गाली दी, और कहा की मैं अपनी घरवाली के पैसे में जी रहा हूँ" इसलिए मुझे गुस्सा आ गया। मुझे कुछ काम मिल जाता तो अच्छा था।"

शीतल कहती है - "कोई बात नहीं", उसके घर देर है अन्धेर नहीं। ईश्वर ने चाहा तो सब ठीक हो जाएगा।"

घर पहुँचते ही शीतल बेहोश होकर गिर गई।

पड़ौसिन ने कहा - 'भैया डॉक्टर के पास ले जाओ।"

मोहन मना कर देता है - वह भाग-दौड़ कर थक गई है, बस थोड़ा आराम कर लेगी, तो ठीक हो जाएगी।

शीतल के मुँह पर थोड़ा पानी छिड़क कर उसे आराम करने के लिए कहता है।

अगले दिन सुबह जब शीतल काम के लिए निकलती है तो उसकी तबीयत थोड़ी खराब महसूस करती है। दुकान जाने से पहले वह पास के क्लीनीक जाकर अपना जाँच करवाती है तो पता चलता है कि वह गर्भवती है।

वह मन में ही सोचती है - सारा पहाड़ एक साथ सिर पर गिरना था क्या? हे ईश्वर !

उस दिन जब वह वापस घर पहूँचती है तो पता चलता है कि जॉनसन वकील ने मोहन को काम से निकाल दिया।

शीतल मन में कहती है - "ईश्वर भी शायद मेरी दुगर्ति पर खुश हो रहे हैं।" शीतल बहुत दुखी हो जाती है। वह अपने गर्भवती होने की बात मोहन को बताती है।

- "अब तो खर्चा ज़्यादा हो जाएगा।"मोहन मुँह बनाकर कहता है ।

शीतल चुप-चाप खड़ी इधर-उधर ताकने लगी। उसका हृदय सत्र हो गया। अपने को ही कोसती रही।

वह अपने दुकान मालिक से अपना दर्द भरा दाँस्ता सुनाती है और अपने पति को कुछ काम देने की भीख माँगती है।

दुकान मालिक कहता है - "कौन उसे अब कोई काम दें। गुंडागर्दी करने वाले से कोई अपना नाता नहीं जोड़ता।"

- वह कोई काम जानता भी है क्या ? दुकान मालिक पूछता है।

- लिखाई-पढ़ाई कहाँ तक की है?

शीतल जवाब देती है - "सर ! उसे ड्राइविंग आती है।"

कुछ देर सोचने के बाद दुकान मालिक शीतल को एक सलाह देते हैं।

- "मैं तुम्हें एक ऑटोरिक्शा दिला दूंगा। पर शर्त है, कि तुम्हारे पगार से आधे रूपये हर महीने काटे जाएंगे। और हाँ उसे भी रोज़ मुझे 500 रुपये देने पड़ेगें।' फिर वे बोले - "जब रकम पूरी हो जाएगी, तो मैं ऑटो तुम्हारे नाम कर दूँगा। "

शीतल झट से मान जाती है। सोचती है चलो कम-से-कम उसका पति घर पर तो बेकार नहीं बैठेगा। रोज़ काम पर जाएगा तो शायद कुछ सुधार जाए।

वह खुशी-खुशी यह खबर मोहन को सुनाती है, वह भी मान जाता है और रोज़ 'ऑटों' चलाने घर से निकलने की बात करता है।

'दो-तीन महीने मोहन रोज़ का किराया दुकान मालिक को देता रहा। पर अचानक एक दिन शीतल की तबीयत कुछ ज़्यादा खराब हो गई और उसे अस्पताल भर्ती करना पड़ा।

डॉक्टरों ने जाँच की और कहा - "जल्दी से ऑपरेशन करना पड़ेगा, बच्चे और माँ की हालत बहुत खराब है।" मोहन से डॉक्टर, रूपयों का इन्तज़ाम करते को कहता है।

मोहन और उसका बाप, रूपयों के लिए इधर-उधर भागते हैं। लेकिन ज़्यादा रूपये जुटा नहीं पाते। 
दोनों तब फैसला करते हैं कि ऑटोरिक्शा को बेच कर कुछ रूपये जुटाया जाए। और बिन दुकान मालिक को बताए केवल तीस हज़ार रूपये में वे अपना ऑटो किसी दूसरे आदमी को बेच देते हैं।

सस्ती मिल रही तो लेने वाले ने भी कुछ आगे न सोची। मोहन ने उसे जल्द ही ऑटो के सारे पेपर देने का वादा किया।

लेकिन देर हो चुकी थी। शीतल भगवान को प्यारी हो गई। वह हमेशा के लिए सो चुकी थी। ज़िन्दगी भर के दुखों का पहाड़ उससे संभाला न गया। अन्तिम-संस्कार के समय मोहन और दिनेश रोने लगे ।

पड़ोसियों ने कहा - "शीतल की आत्मा को शान्ति मिले।" बहुत कुछ सहा है उस बेचारी ने अपने इस छोटी सी उम्र में।"

मोहन बोला - "भगवान ने उसे सब दुखों से मुक्त कर दिया उसकी आत्मा को मोक्ष दे दिया।"

सब लोग फिर अपने-अपने घर चले गये। दूसरे दिन दोनों बाप-बेटे, वहाँ से फरार हो गये।

उन दोनों की नौ दो ग्यारह होने की खबर गाँव में फैल गई। हैं।

यह आधुनिक युग की कहानी, प्रेमचन्द की कहानी "बुधिया", "घीसु" और "माधव' की ही है। बस कुछ वातावरण में परिवर्तन हुए

जिस तरह प्रेमचन्द ने अपने समय के गरीबों की गरीबी में पिसने के कारण बेईमान और आलसी हो जाने की बात कही, वही आज के ज़माने में भी चली आ रही है, बस पात्रों के नाम बदल गये और कुछ हालात में बदलाव आ गया है।

लेकिन गरीबी में जीने वाला, समाज के आचार-व्यवहार, निन्दा, धिक्कार आदि की चिन्ता तब भी नहीं करता, और आज भी नहीं करता। काम की कमी नहीं है। घर में फोंके की तौबत आ जाती तो दोनों बाप-बेटे काम करने निकल पड़ते हैं। मोहन ड्राइविंग जानता है तो बस वह वही काम करेगा। $\quad$ बी.ए. पास होने के बाद भी शीतल सेल्सगर्ल का काम करती है।

प्रेमचन्द की कहानी "बुधिया" में घीसू और माधव की अकर्मव्यता, अमानवीयता की चरम स्थिति का चित्रण किया है, यहाँ भी मोहन और दिनेश इसी खेत की मूली हैं। घीसू और माधव की तरह दोनों में थोड़ी मानवीय संवेदना भी है।

जो लोग दान, धर्म, उदारता का नाटक करते है, उनकी कमी आज भी बिल्कुल नहीं है। प्रेमचन्द ने भी उस व्यवस्था के चरित्र को उजागर किया है, जो दोनों हाथों से गरीबों को लूटते हैं। गरीब अपनी स्थिति को नियती का खेल मानकर उसे स्वीकार करके बदहाली में जीते रहे हैं। क्योंकि श्रम की कोई सार्थकता उन्हें नज़र नहीं आती या नसीब नहीं होती। औरत के मरने पर, अन्तिम संस्कार के समय रूपये हाथ में आने पर उनकी नियत बदलने लगती है।

गरीबों की मानसिकता, उनकी सोच और उनके आर्थिक स्तर पर बदलाव लाना ज़रूरी है, सुधारना ज़रूरी है।

प्रेमचन्द ने अपनी लेखनी द्वारा जिन वातावरण का निर्माण करके पाठक की आँखों के आगे सारा दृश्य साकार किया था, वही द्यश्य आज भी साकार है। क्योंकि कोई भी लत जो सीमा से अधिक हो, वह बूरी और विनाशकारक होती है। बूरी लत में व्यक्ति का ईमान, धर्म, समाज, आदि के प्रति उसके कर्तव्य का 'लोप' हो जाता है। ऐसी बूरी लत के शिकार - व्यक्ति धिक्कार के योग्य होते है। आज के समाज में भी हमें कई ऐसे लोग दिख पड़ते हैं। जो कभी दया के पात्र नहीं होते। लेकिन ऐसे पात्रों को समाज की सामाजिक स्थिति ही पैदा करती है।

\section{SOURCES OF FUNDING}

This research received no specific grant from any funding agency in the public, commercial, or not-for-profit sectors.

\section{CONFLICT OF INTEREST}

The author have declared that no competing interests exist.

\section{ACKNOWLEDGMENT}

None. 